\title{
Achieving Sustainable Value Planning For Malaysian Public Projects
}

\author{
Faudzi Muhammad ${ }^{1, a}$, Rohana Mahbub ${ }^{1}$, Abdul Hadi Nawawi ${ }^{1}$ and Nazirah Zainul Abidin ${ }^{2}$ \\ ${ }^{1}$ Faculty of Architecture, Planning and Surveying, Universiti Teknologi MARA (UiTM), 40450 Shah Alam, Selangor, Malaysia \\ ${ }^{2}$ School of Housing, Building and Planning, Universiti Sains Malaysia (USM), 11600, Penang, Malaysia
}

\begin{abstract}
Sustainability is the central development issue in the modern economy. Through sustainable development, quality of life can be improved or maintained over time. Since Malaysia is targeting to become a high-income nation by the year 2020, financial investment in public projects should be planned comprehensively so that it will generate immediate and long-term benefits to the country and the people. Within the currently tight financial environment, achieving value for money in public spending is seen as one of the enablers to maintain the right momentum of economic growth. Previous studies have established the importance of integrating sustainability consideration into Value Planning protocol in order to achieve value for money, underpinned by the sustainable development agenda. Despite the establishment of the framework for the integration, the opportunity of such integration within the Malaysian Value Planning protocol for public projects remains unclear. The present state of sustainability consideration within the Value Planning practice should be first evaluated, so that potential interventions to enhance the integration can be introduced. Responding to the gap, this exploratory study was conducted. The data was collected by means of document analysis, interviews and observations; subsequently analysed using the Template Analysis technique. Based on the current practice of Value Planning in Malaysia, ten interventions are proposed to transform the present practice into Sustainable Value Planning. Sustainable Value Planning is seen as a comprehensive concept in achieving value for money in public spending underpinned by the overarching concept of sustainability
\end{abstract}

\section{Introduction}

In modern economy, sustainability has become the central issue in improving the quality of life. Sustainability is the result of Sustainable Development; and defined as the capability of continuity [1]. It is formed by the Triple Bottom Line themes of economy, society and the environment [2]. In the global arena, the World Economic Forum introduced the Sustainability Adjusted Global Competitiveness Index in 2012 as complementary information to the traditional Global Competiveness Index (GCI) in comparing the economic performance between countries around the globe [3]. In this evaluation system, the economic performance of a particular country is not measured solely based on its competitiveness score; rather, the social sustainability coefficient and environmental sustainability coefficient are integrated into the competitiveness score in order to get the sustainability adjusted GCI score. Within the Malaysian context, the New Economic Model (NEM) adopted Sustainability as one of its goals beside highincome target and inclusiveness in order to consistently improve the people's quality of life [4].

Malaysia has officially recognised sustainability as its national development agenda since 1981 through the Forth Malaysia Plan [5]. Targeting the right momentum to achieve high-income nation status by the year 2020,

\footnotetext{
a Corresponding author: faudzimd@gmail.org
}

the cur Malaysia Plan highlights a few initiatives to encapsulate all efforts towards sustainable development as underpinned by the NEM. Amongst others, Value Management (VM) has been chosen as the strategic management tool to achieve value for money in government development programmes and projects [6]. Within the context of construction projects, the EPU Circular No 3/2009 [7] made it mandatory for all government projects worth RM50 million and above to undergo the VM Study starting from the year 2010. In general, VM is a structured multi-disciplinary value methodology aiming for resources optimisation in achieving the predetermined project functional specification at the acceptable level of quality $[8,9]$. It focuses on selecting the most economical solution from various alternatives resulting in the same quality of functions. By analysing the functional needs of the project system and its sub-systems, wastages can be identified and eliminated. The main focus of VM is to get the lowest possible investment on a particular project without compromising its functional performance and quality [10].

According to the EPU VM Guide, VM in the context of Malaysian public projects is an umbrella term that covers all types of Value Studies conducted in accordance to the internationally recognised value methodology. These value studies can be categorised as 
Value Planning, Value Engineering and Value Review based on its focus and the moment at which the study is conducted [11]. Based on the project context, Value Planning is the front end VM and conducted during the early project planning stage. Due to various advantages of considering sustainability needs during the early project planning stage [12], Value Planning provides a perfect opportunity to integrate sustainability considerations into project proposals. Despite its strategic opportunity, there is no direct indication found in any major government policies or circulars demanding sustainability integration within Value Planning. However, it might not necessarily mean that Value Planning in Malaysia does not consider sustainability issues at all. Hence, the actual state of sustainability integration within the Malaysian Value Planning remains unclear. Without such knowledge, initiatives to nurture the integration of sustainability and Value Planning could not be effectively planned.

In this case, a dedicated exploratory study that explores the scenario within its original setting is required $[13,14]$. Responding to the need, this study is conducted; where it aims to answer the questions of (1) "What is the state of sustainability integration within the Malaysian Value Planning?" and (2) "What are the potential interventions that might nurture the integration of sustainability considerations into the Value Planning practice in Malaysia?" In order to achieve the aim of this study, two objectives have been identified to steer the flow of the study; the two objectives are:

- To explore the current state of sustainability integration within Malaysian Value Planning

- To propose potential initiatives towards Sustainable Value Planning in Malaysia

\section{Sustainable Value Planning}

Sustainable Value Planning introduced by this paper is a conceptual model resulting from the expansion of the original works by Zainul Abidin in integrating sustainability considerations into Value Study practice $[1,15,16]$. It is learnt that integrating sustainability considerations into Value Study would include input of sustainability, processing sustainability and output of sustainability. Input of sustainability refers to the scenario where sustainability awareness is being imbedded into the scope of the Value Study. Processing Sustainability is where the sustainability themes that reflect the economic benefit, social wellbeing and environmental protection are integrated into the Value Study process. Output of sustainability highlights the quality of the projected outcome of the Value Study's product that consists of tangible and intangible values of the proposed project. In other words, output of sustainability defines the perceived project sustainability performance based on the development proposal conceived through the Value Study. Based on the findings, a conceptual framework for integrating sustainability issues into Value Planning has been introduced by Zainul Abidin and reproduced in Figure 1.

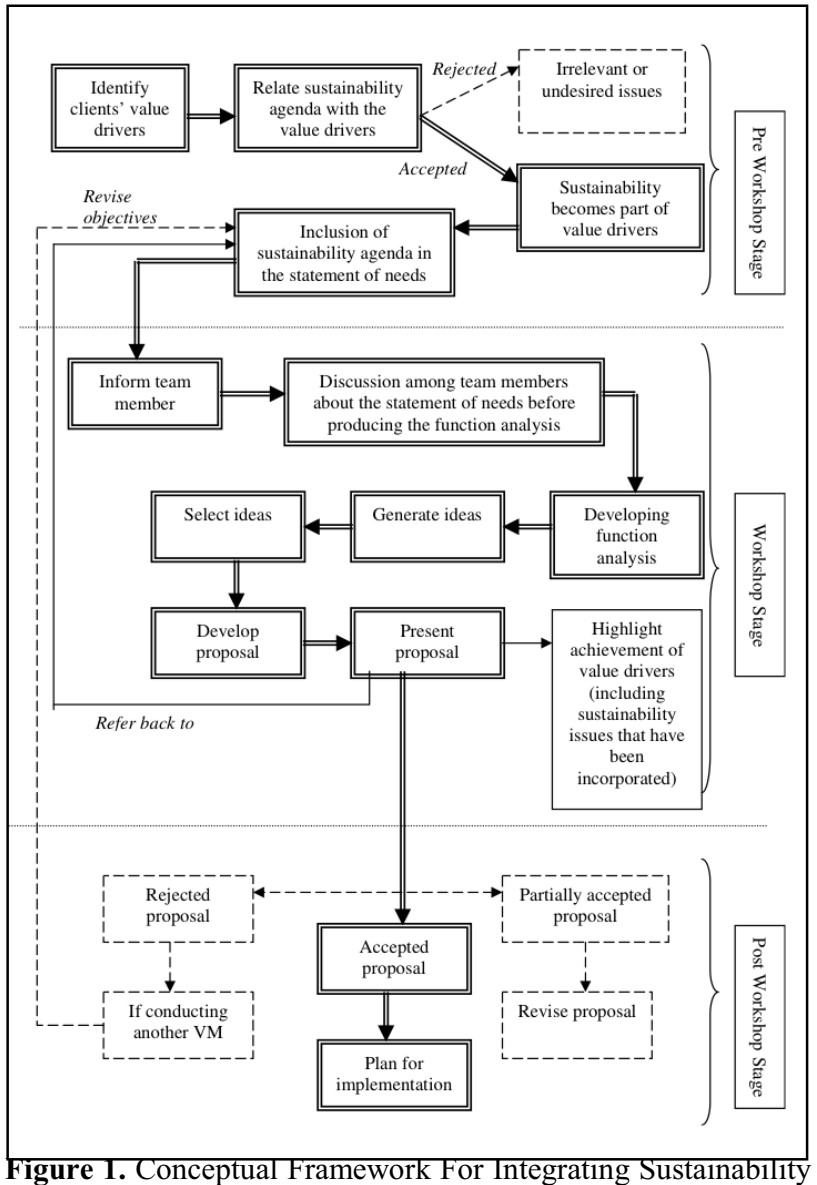

Issues Into Value Planning

Source: Zainul Abidin (2005), Page 179

Through this conceptual framework, the importance of recognising sustainability as part of the value drivers, working with sustainability themes during the course of the study and highlighting the sustainability features for project proposal have been established in order to efficiently integrate sustainability considerations into the Value Study. Although the framework uses the VM terminology to represent the value study, it actually refers to Value Planning since the study was conducted on the VM studies carried out during the early project planning stage. As sustainability deals with meeting present needs without jeopardising the ability of future generations to meet theirs [17], Sustainable Value Planning can be defined as the Value Planning that recognises sustainability themes as its value drivers with the aim to help improve quality of life. Based on this definition, Sustainable Value Planning is concerned about the achievement of the project outcomes on top of traditional Value Planning that focuses on achieving value for money through fulfilling the project objectives. Since Value Planning is conducted during early project planning stage with the structured involvements of key stakeholders as well as experts in various field of knowledge, it is the most suitable moment to integrate sustainability considerations into the project proposal.

The Sustainable Value Planning concept leans towards achieving positive economic, social and environmental impacts of project variables such as design 
concept, material selection and delivery systems of the construction and facility management to respond towards present and future needs. Due to this nature, problems associated with sustainability issues are ambiguous and unstructured. The whole process of integrating sustainability considerations into the Value Planning process requires dynamic learning processes within the Value Team that involves the real-world view and systems thinking. Due to its complexity, cost savings resulting from the Value Study could not adequately explain the performance of Sustainable Value Planning. In this regard, Simple Multi-Attributes Rating Technique (SMART) VM [18] provides an appropriate framework for Sustainable Value Planning. In SMART VM, multiattributes are used as the decision criteria in choosing the best project proposal option. Green advocated SMART $\mathrm{VM}$ as an innovation to the traditional single attribute $\mathrm{VM}$, where cost is the only determining criterion in selecting options [19].

Just like SMART VM, Sustainable Value Planning should be conducted based on the Soft System Methodology (SSM) paradigm. SSM combines cognitive system thinking and real world perspective in predicting the appropriate solutions for unstructured problems [20]. Figure 2 shows the graphical representative of SSM where the unstructured problem perceived from the real world is analysed and solved through appropriate conceptual models embedded within the individual participant of the Value Study. In this case, Sustainable Value Planning requires the involvement of the right people with the right knowledge and experience. Besides that, the success of Sustainable Value Planning is determined by the ability of the Value Team to nurture dynamic learning processes through effective knowledge sharing amongst the multi-disciplinary Value Team.

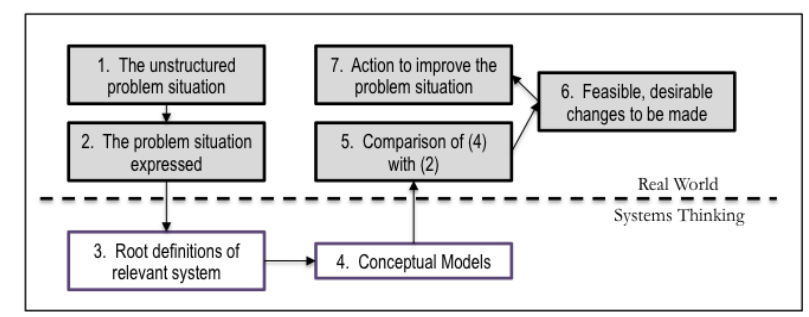

Figure 2. The Soft System Methodology Source: Adapted from Checkland (1981)

\section{Methodology}

This study is considered as an exploratory study; an exploratory study is a study "that aims to seek new insights into phenomena, to ask questions, and to assess the phenomena in a new light" [13]. To conduct this exploratory study, three data collection methods were adopted namely documentary analysis, observation and interview. Documentary analysis involves desktop analysis of relevant documents and department records relevant to the Value Planning practice for public projects in Malaysia. Five previous Value Assessment Laboratory Reports have been analysed thoroughly besides other department records archived in the Value Management
Section of the Economic Planning Unit Malaysia (VMSEPU). The Economic Planning Unit (EPU) is the central government agency under the Malaysian Prime Minister Department responsible to plan, monitor and evaluate the economic development agenda of the country. Subsequently, controlling the public development expenditure is also one of the agency's responsibilities. A series of semi-structured interviews have been conducted involving the VM practitioners as well as the VMS-EPU officials. In Malaysia, VMS-EPU officials facilitate the Value Assessment Laboratories for public projects. While VM practitioners provide general understanding about the VM concept, VMS-EPU officials provide in-depth information regarding the Value Planning practice for public projects in Malaysia. There were eight participants involved with the series of interview sessions. At the end of the sessions, observations involving five Value Assessment Laboratories for public projects at its practical setting were conducted. These observations covered Value Assessment Laboratories for various natures of projects, from purely building to purely infrastructure construction that were selected for the purpose of this study. As data collected in this study are qualitative in nature, they are analysed using the qualitative data analysis technique. For this reason, the Template Analysis [21] is used. Data collection and analysis in this study have been conducted concurrently to ensure templates are induced dynamically based on the themes emerging throughout the knowledge development process, while available theories provide theoretical underpinning during the analysis process. As validity is one of the five important elements in qualitative research [22], consensus expert validation has been used to ensure the validity of the research's findings (the developed knowledge).

\section{The State Of Sustainability Integration Within Malaysian Value Planning}

From documentary analysis, it is found that sustainability integration within public project planning in Malaysia is well captured by the Logical Framework Analysis (LFA) Approach introduced by EPU Malaysia through its Circular No $1 / 2009$ [23]. Based on the circular, it is mandatory for every project proponent to conduct the LFA before submitting the proposal for budget approval. Figure 3 shows the summary of LFA for public projects in Malaysia. Based on the circular, the project proponent should develop a project brief for the proposed project to be endorsed at the ministerial level before it is submitted for the budget approval process. The endorsed project brief should be submitted to the EPU through the SPP-II system. A comprehensive project brief should include all items as required by the said circular; the content of the project brief is shown in Figure 3 (Phase 3). The LFA consists of three sequential phases and the project brief is the final product of the LFA. Within Phase 2 of the analysis, the project proponent is required to analyse sustainability considerations of the proposed project that includes financial, economic, social and environmental 
issues. Before finalising the project brief, a project decision matrix should be established. With in-depth understanding of the sustainability and value concepts, the project decision matrix will induce the project value drivers.

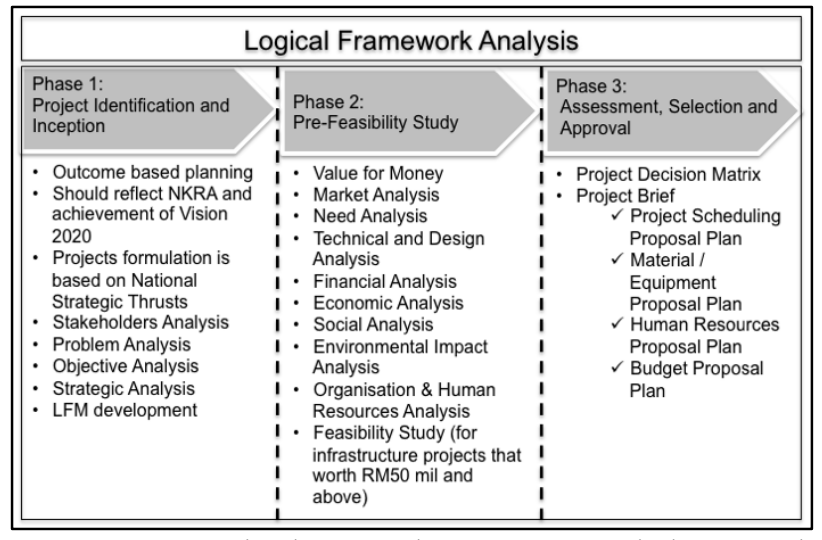

Notes: NKRA = National Key Result Area; LFM = Logical Framework Matrix

Figure 3. Logical Framework Analysis for Public Project Planning in Malaysia

Source: EPU Circular 1/2009

LFA provides good foundation in linking the project objective, expected outcome and the national development agenda. However, through interviews and observations, it is found that the LFA is only used extensively during the Budget Examination Process; which is the first process in evaluating the potential benefits of the proposed project. Although the Budget Examination process involves key stakeholders of the proposed project, it is conducted within a normal meeting setting and the six phases of the value job plan are not involved. Besides that, it is also found that the Budget Examination Process for a particular project is conducted during a meeting lasting just a few hours which is significantly less than the suggested Value Study duration of 40 effective hours. The meeting involves representatives from key stakeholder departments at senior management level. Due to limitation of time, the Budget Examination Meeting does not comprehensively challenge the assumptions made by the proponent while developing the project brief. The main focus of the Budget Examination Meeting is to evaluate the significance of the proposed project at macro level and to identify its potential contributions to the national development agenda. Normally, the meeting will focus on evaluating the expected outcomes and objectives of the project. Technical items such as cost modelling and proposed scope of the project are not comprehensively discussed during the meeting. Projects with high economic potential (normally those directly related to the National Key Economic Areas) and those directly related to the National Key Result Areas of the Government Transformation Programme will be given high priority for budget allocation. Subsequently, projects that worth RM50 million and above or any other projects deemed to be necessary by the committee will be subjected to Value Planning exercise.
Based on the provisional budget approval through the Budget Examination Process, Value Assessment Laboratory will be conducted with the collaboration of the VMS-EPU. The Value Assessment Laboratories are normally conducted at any moment between the stages of 'Preparation \& Brief' to 'Developed Design' of the 2013 RIBA Plan of work. However, there are also isolated cases where Value Planning is conducted during early construction stage. In most cases, Value Planning is conducted when VMS-EPU believes that most of the required data, information and knowledge have been accumulated for the proposed project which enables the Value Team to define the perceived problems faced by the project.

During the Value Assessment Laboratory, project parameters are thoroughly discussed and registered in the laboratory templates of 'Project Must', 'Project Given', 'Project Constraint', 'Project Objective' and 'Project Outcome'. Since the 'Project Objective' and 'Project Outcomes' have been established through the LFA, project's sustainability themes can be identified especially within the 'Project Outcome'. Through observations of the five Value Assessment Laboratories, none of them had shown comprehensive analysis of the project outcomes. Normally, the proposed project outcomes will be revisited superficially and endorsed by the laboratory and subsequently registered in the final report. The laboratory emphasises more on the proponent's proposal in achieving the project objectives; this would include evaluating the proposed development cost model as well as the suggested project scope.

Through observations, it is found that the Function Analysis System Technique (FAST) Diagram is not used as a tool during the Function Analysis Phase. FAST Diagramming is a process of logical thinking about the entity as a system and its elements as sub-systems reacting to one another in order to serve the purpose of its existence [24]. With the FAST Diagram, relationships between lower and higher order functions can be explicitly presented. Since Value Assessment Laboratory skips the FAST Diagraming, the Information and Function Analysis Phases of the laboratory seem to be integrated as a single phase where the value team focuses on identifying the project components without considering the importance of the components in achieving the value drivers. Besides that, value drivers are not explicitly discussed and registered during the laboratory. However, since most of the Value Team members are experienced and knowledgeable enough in the nature of the proposed project in all the observed laboratories, the teams have no problem inducing the required project components.

Through observations, it is learnt that the Value Teams induce the project value system based on individual tacit knowledge or solely based on the proponent's original proposal. The danger of using this approach is that public projects in Malaysia might become trapped in the traditional way of doing things, thus limiting the possibility of innovation in the project delivery system. With this approach, the possibility that public projects inherit the recurring problems is high since they are actually adopting the same conceptual 
models in the project delivery system. This can be seen where most of the ideas accumulated during the Creativity Phase are limited to the project sub-systems level rather than at the project system level. Based on this finding, the Malaysian Value Planning currently leans toward hard system methodology where the ontological aspect of the project system remains untouched.

Since value drivers are not well articulated during the earlier laboratory phases, the Evaluation Phase could only rely on the single-criterion basis in evaluating the accumulated ideas generated during the Creativity Phase; the criterion is the cost implication of the ideas. Although there are efforts identified to evaluate the ideas based on advantages-disadvantages analysis, they are not structured and very much dependent on the subjective interpretation of the team members. Besides that, there are also people with strong characters trying to manipulate the team to accept ideas beneficial to one particular party using the cost sentiment. In the end, cost related comments are found within the advantages and disadvantages columns of the evaluation report such as 'it reduces the project cost' or 'it increases the project cost'. Although there are good ideas accumulated through the Creativity Phase and then evaluated during the Evaluation Phase, it is observed that ideas that challenge the whole project delivery system are limited. From this, it can be concluded that the Value Planning in Malaysia is very much cost oriented.

During the Development Phase, it seems that sustainability features are not well captured within the action plan. There is no clear indication on how the newly conceived project proposal would enhance the achievement of the project's expected outcomes. As most of the sustainability considerations are embedded within the expected project outcomes, thorough analysis on the project proposal towards the achievement of its expected outcome is crucial to highlight the sustainability performance of the new proposal. Within the existing standard template for Value Assessment Laboratory, there are only two items highlighted in the summary sheet; they are the variance of project cost as well as the variance of the project scope by comparing the original proposal and the new proposal conceived by the laboratory. With this information, it is difficult to conclude whether the newly conceived proposal really enhances the project value performance. More importantly, the existing practice of Value Planning fails to highlight contributions of the new proposal towards the national development agenda. In general, it is found that sustainability issues are integrated in some parts of the Malaysian Value Planning. However, the integration in most of the cases is unintentional and unstructured. Hence, Value Planning is Malaysia could not yet to be classified as Sustainable Value Planning.

\section{Intervention Needed To Transform Current Practice}

Although sustainability integration within the current practice of Value Planning in Malaysia is limited, the potential to achieve Sustainable Value Planning is evident. In order to transform the current practice of Value Planning for public projects into Sustainable Value Planning, ten interventions are identified and will be proposed through this study. The following sub-topics will discuss each intervention separately.

\subsection{Establish A Permanent Panel Of Sustainability Experts}

In order for Value Planning in Malaysia to address sustainability issues, experts in the field of sustainability should be involved throughout the laboratory sessions. The experts should be identified and a permanent panel of sustainability experts should be formed to provide consultancy regarding sustainability issues for Malaysian Value Planning. These experts should be able to provide accurate knowledge to the Value Team regarding the sustainability concept and are able to forecast the sustainability impact of the proposal conceived by the Value Team. As sustainability is an overarching concept that integrates the three inter-related pillars of economic, social and environmental issues, it involves metacognitive knowledge. Metacognitive knowledge is described as strategic knowledge that involves one's ability to manipulate the cognitive tasks of remembering, understanding, applying, analysing, evaluating and creating [25]. While the fragmented individual knowledge of economics, humanistic and environmental ecology might provide factual, conceptual and procedural knowledge to the Value Team, metacognitive knowledge helps the team to answer the 'how' and 'why' questions to the perceived problems. Current Value Planning practice might involve quantity surveyors as cost estimation experts, officials from the local authority as the local social experts and officials from the Department of Environment as the environmental experts; they might come with pieces of information and knowledge that need to be organised and integrated. It is the task of the sustainability panel to analyse and synthesise the fragmented body of knowledge, thus creating the conceptual models. Using these conceptual models as input, the overall learning process within the Value Team can be enhanced and new knowledge can be created.

\subsection{Introduce Sustainability Concept To The Value Team}

In order for the Value Team to appreciate the need to integrate sustainability considerations during the laboratory process, awareness regarding the need should be first established. It is found that lack of right knowledge regarding sustainability is one of the main barriers to integrate sustainability into Value Studies $[15,26]$. Some examples of misconceptions about the sustainability concept are sustainability is all about green buildings, or sustainability is to ensure that the project could be financially sustained in the long-run, or 
sustainability is achieved when the project uses expensive green technology products, or the overall design is blended with the natural landscape. These are actually the examples of sustainability solutions to the project and not the sustainability themes to be considered during the planning process. It should be emphasised that sustainability solutions are the result of sustainability considerations depending on availability of resources and the actual needs of the project, which are explained by the value themes as part of the project's value drivers.

\subsection{Highlight Value Drivers To The Value Team}

Value drivers are the key factors that drive the direction of value creation within the value system [27]. They define the client value system and highlight value goals to be achieved by the value study. As Malaysia is pursuing the Sustainable Development agenda [6], the value drivers for public projects in Malaysia should inherit sustainability themes. Value drivers help to explain the relationships between function specifications of the particular project and the definition of project quality; or in simpler terms it helps to articulate the relationships between project objectives and the expected outcomes. Project outcomes for public projects in Malaysia should incorporate sustainability issues [23] as the performance of any Value Planning for public projects in Malaysia is much related to the ability of the laboratory to identify and propose relevant solutions to sustainability problems. While sustainability problems are complex and unstructured in nature, the availability of value drivers might help to define the roots of the problems. With the adoption of SSM and availability of sustainability experts, the Value Assessment Laboratory will be able to identify sustainability solutions based on the interaction of the world-view and systems thinking.

\subsection{Establish Value Network That Explains The Project Value System}

In order for the Value Team to conceive an efficient project proposal, they should be clearly informed about the project objectives, expected outcomes, constraints, function specifications and boundaries. The present practice successfully captures these pieces of information using the relevant templates. However, the relationship between these variables with the project value system is still vague. It is very helpful for the Value Team if the project value system can be explicitly shown in a single framework. With this framework, the value network can be identified, thus helping the laboratory participants develop new knowledge during the dialogue session. The FAST Diagram and the Value Tree Diagram are examples of Value Network Diagrams that explain the project value system. Despite the success of the current practice in producing laboratory reports at the end of the laboratory sessions without the assistance of the FAST Diagram, the project value system could not be easily understood by people who are not physically involved during the laboratory process. Since Value Planning is conducted at the early planning stage, it is crucial to ensure that the developed knowledge is disseminated throughout the project lifecycle. Besides that, the value network should be shared between laboratories to nurture the continuous learning process in improving the value of public projects.

\subsection{Include Project Outcome Analysis As Part Of The Laboratory Scope}

In all of the laboratories observed, project outcomes are not comprehensively analysed during the laboratory sessions. The reason is that many facilitators belief that analysing the project outcome is not within the scope of Value Assessment Laboratory and it has been previously endorsed during the Budget Examination Process. Although this perception is to some extent acceptable, it is not entirely accurate. Besides function and cost, value is also related very much to the quality of the project [11]. In the context of public projects, the quality of the project is determined by its outcomes [23]. Thus, it is important for the Value Assessment Laboratory to analyse the expected outcomes of the project through a structured and rigorous process. Towards that, the scope of Value Assessment Laboratory should be expanded to include structure analysis of the project outcomes. This inclusion will help the Creativity Phase of the laboratory to generate radical yet practical ideas in achieving the project outcomes and challenge the suggested objectives. Thus, the new proposal might explore innovations at project system level.

\subsection{Determine Evaluation Criteria Based On Value Drivers}

Evaluation criteria are important for Sustainable Value Planning since the broadness of sustainability concept might lead to multiple interpretations. Since sustainability involves multiple themes, it is important to determine the weightage of each theme within the project context. The Decision Matrix [19] is one of the evaluation models that can be used during the Evaluation Phase. To ensure coherence within the Value Study, evaluation criteria should be developed based on the project's value drivers and directly related to the Project Decision Matrix developed during the LFA.

\subsection{Evaluate The Pereived Sustainability Peformance Of The Project}

The quality of the laboratory product should be evaluated to highlight its contributions towards the national development agenda. The Perceived Project Sustainability Performance Indicators (PPSPI) can be used as the measurement indicator for this purpose since it has considered major government policies based on the Triple Bottom Line themes and was specifically developed for Malaysian Value Planning [28]. The PPSPI is shown in Figure 4. The 25 indicators seem to 
be flexible and comprehensive enough to visualise the sustainability performance for almost all kinds of public construction projects.

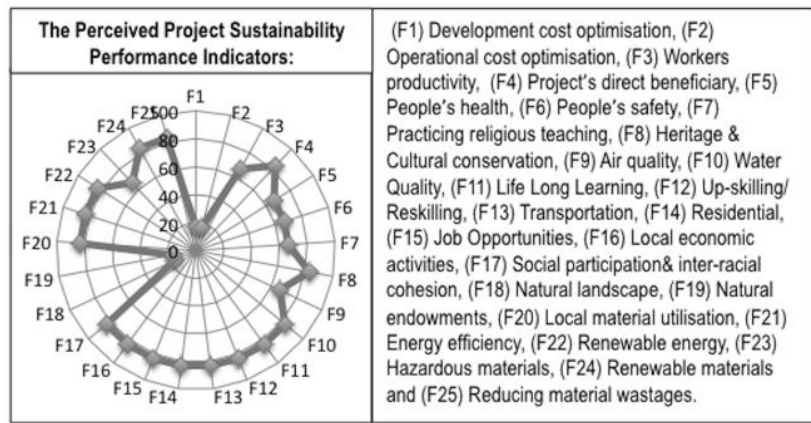

Figure 4. Perceived Project Sustainability Performance Indicator For Value Planning In Malaysia

Source: Wawawi et al. (2015)

\subsection{Highlight Sustainability Performance Of The Project To Key Stakeholders}

Sustainability performance of the proposed project based on its newly conceived proposal should be highlighted to the key stakeholders during the Presentation Phase. The reason for this is to promote sustainable development awareness for public projects in Malaysia as well as to rationalise wrong perceptions about Value Management. Besides that, it helps to rationalise the variance in project costs as well as the project scope.

\subsection{The Perceived Project Sustainability Performance Indicator (PPSPI) To Be Used As Standard Performance Evaluation System For Value Planning In Malaysia}

The PPSPI [28] should be used as the standard performance evaluation system for Value Planning in Malaysia. It is suggested that the Sustainability Expert Panel and key stakeholders of the project involved during the laboratory session become the assessors of the newly conceived proposal. The marked radar chart can be used as the graphical representation of the PPSPI result. Figure 4 shows the example of the suggested Perceived Sustainability Performance Report.

\subsection{Embed Value Audit Within The Project Action Plan}

To ensure that the development proposal conceived through Value Planning transpires in the design, construction as well as operational stages, audits should be conducted at reasonable milestones. Although Value Review (VR) is considered as the value audit for the project, it can only be conducted upon the maturity period of the facility operation [11]. Thus, VR could not be used as a mechanism to ensure that the proposal is accurately interpreted during the design and construction stage. As sustainability initiatives are a continuous process throughout the project life cycle [12], scheduled value audits might be the best platform to ensure sustainability features introduced through Value Planning is well captured throughout the project life cycle.

\section{CONCLUSION}

It is found that sustainability integration within the current practice of Value Planning for public projects in Malaysia is still limited. In order to nurture the integration, the current practice needs to be transformed. It is believed that Sustainable Value Planning can be achieved in Malaysia with minimum modification of the current practice. Towards that, ten interventions should be strategically integrated into the current Value Assessment Laboratory protocol. Figure 5 shows the overall framework to transform the current practice of Value Planning for public projects in Malaysia into Sustainable Value Planning. Besides the ten interventions, the laboratory facilitator should consistently promote effective knowledge sharing within the multi-disciplinary Value Team to nurture team synergetic relationship as well as enhancing the dynamic learning process. The ten interventions can be strategically embedded into the input, process and product of the Value Planning practice.

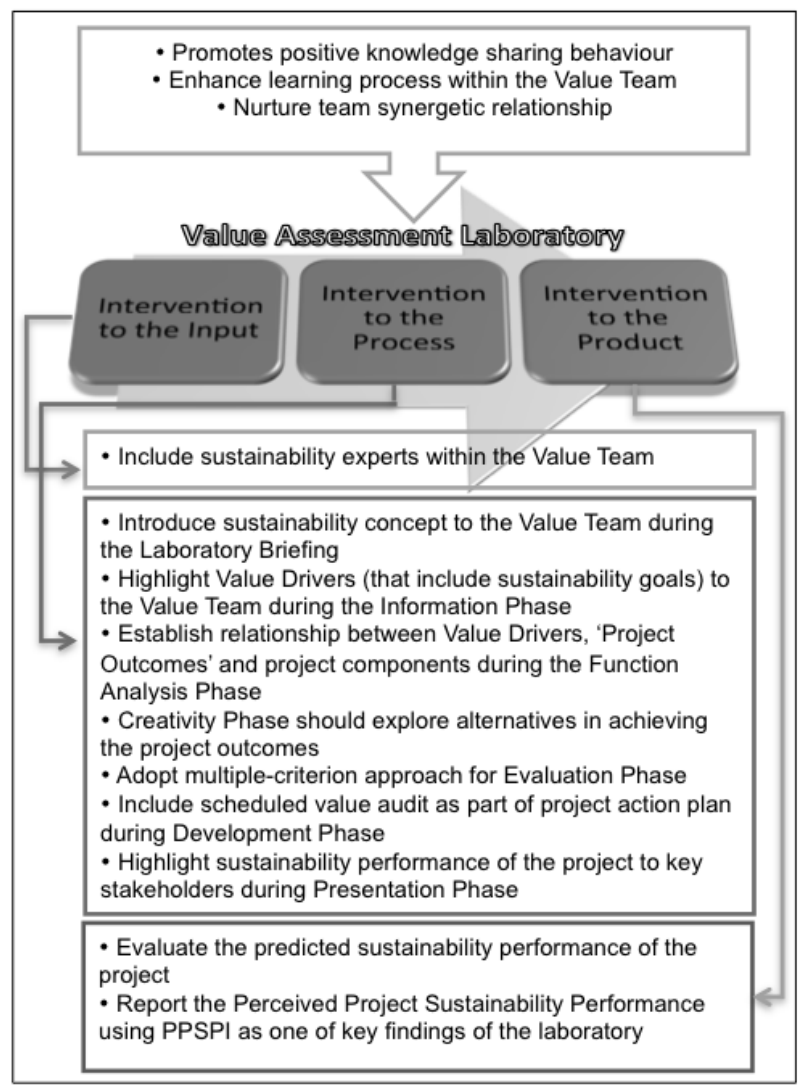

Figure 5. Strategic Intervention To Achieve Sustainable Value Planning For Malaysian Public Projects 


\section{References}

1 N. Zainul Abidin. Using Value Management To Improve The Consideration Of Sustainability Within Construction, PhD thesis, United Kingdom: Loughborough University. (2005)

2 M. Kucukvar, G. Egilmez, O. Tatari. Sustainability Assessment of U.S. Final Consumption And Investments: Triple-Bottom-Line Input-Output Analysis. Journal of Cleaner Production, 81. 234243. (2014)

3 B. Bilbao-Osorio, J. Blanke, R. Crotti, M. D. Hanouz, B. Fidanza, T. Geiger, C. Ko and C. Serin. Assessing The Sustainable Competitiveness of Nations. The Global Competitiveness Report 20122013, 49-63. (2012)

4 NEAC Malaysia: National Economic Advisory Council of Malaysia (2010). New Economic Model for Malaysia - Part 1. Percetakan Nasional Malaysia Berhad.

5 EPU Malaysia: Economic Planning Unit of Malaysia. Forth Malaysia Plan: 1981-1985. (1981)

6 EPU Malaysia: Economic Planning Unit of Malaysia. Tenth Malaysia Plan: 2011-2015. (2010)

7 EPU Malaysia: Economic Planning Unit of Malaysia. Pekeliling 3/2009: Garis Panduan Pelaksanaan Pengurusan Nilai (Value Management) (2009)

8 SAVE International, Value Methodology Standard and Body of Knowledge. (2007)

9 Standards Australia, AS 4183-2007: Value Management. (2007)

10. J. Kelly, S. Male and D. Graham,. Value Management of Construction Projects; Second Edition, John Wiley \& Sons. (2014)

11. EPU Malaysia: Economic Planning Unit of Malaysia. Panduan Pelaksanaan Pengurusan Nilai dalam Program/Projek Kerajaan. (2011)

12. RIBA. RIBA Plan of Work 2013: Overview. (2013)

13. M. Saunders, P. Lewis, A. Thornhill. Research Methods for Business Students: Sixth Edition. Pearson. (2012)

14. J. W. Creswell and V. L. Plano Clark. Designing and Conducting Mixed Methods Research: Second Edition. Sage Publications. (2011)

15. N. Zainul Abidin and C. L. Pasquire. Delivering Sustainability Through Value Management: Concept And Performance Overview. Engineering, Construction and Architectural Management, 12(2), 168 - 180. (2005)

16. N. Zainul Abidin and C. L. Pasquire. Revolutionize Value Management: A Mode Towards Sustainability. International Journal of Project Management, 25, 275-282. (2007)

17. The World Commission on Environment and Development - United Nations. Our Common Future. (1987)

18. S. D. Green. A SMART Methodology For Value Management. Occasional Paper, Chartered Institute of Building 53, UK. (1992)
19 S. D. Green. Beyond Value Engineering: SMART Value Management For Building Projects, International Journal of Project Management, 12 (1), 49-56. (1994)

20. P. Checkland. Systems Thinking, Systems Practice. USA: John Wiley. (1981)

21. N. King. Using Templates in the Thematic Analysis of Text. In C. Cassell, and G. Symon, (Eds). Essential Guides to Qualitative Methods in Organizational Research. Sage Publications. (2004)

22. J. A. Maxwell. Qualitative Research Design - An Interactive Approach: Third Edition. Sage Publications. (2013)

23. EPU Malaysia: Economic Planning Unit of Malaysia. Pekeliling 1/2009: Garis Panduan Perancangan dan Penyediaan Program dan Projek Pembangunan. (2009)

24. F. Wojciechowski, The Various Types and Uses Of The FAST Diagram. Proceedings of the SAVE Conference. 153-159. (1978).

25. L.W. Anderson, D.R. Krathwohl, P.W. Airasian, Cruikshank, K.A., Mayer, R.E., Pintrich P.R., Raths, J., Wittrock, M.C. A Taxonomy For Learning, Teaching, And Assessing: A Revision Of Bloom's Taxonomy of Educational Objectives. New York: Longman. (2001)

26. Y.M. Al-Saleh, and H.M. Taleb. The Integration of Sustainability Within Value Management Practices: A Study of Experienced Value Managers in the GCC Countries. Project Management Journal, 41(2), 50-59, (2010)

27. S. Bose, and K.B. Oh. Measuring Strategic ValueDrivers For Managing Intellectual Capital, The Learning Organization, 11(4/5), 347-356. (2004)

28. Nawawi, A. H., Muhammad, F., Mahbub, R. and Zainul Abidin, N., Perceived Project Sustainability Performance Indicator For Value Planning, Procedia - Social and Behavioural Sciences, 202, 89-97. (2015) 